\title{
1 Does timing of birth affect juvenile and mare survival in
}

\section{2 wild plains zebra?}

4 Lucie Thel $^{1}$, Christophe Bonenfant ${ }^{1,4}$ \& Simon Chamaillé-Jammes ${ }^{2,3,4}$

$6{ }^{1}$ Laboratoire de Biométrie et Biologie Évolutive, Unité Mixte de Recherche 5558, Bâtiment 7 711, Université Lyon I, Villeurbanne Cedex, France.

$8 \quad{ }^{2}$ CEFE, Université Montpellier, CNRS, EPHE, IRD, Montpellier, France.

$9{ }^{3}$ Mammal Research Institute, Department of Zoology and Entomology, University of Pretoria, 10 Pretoria, South Africa.

$11{ }^{4}$ LTSER France, Zone Atelier "Hwange", Hwange National Park, Dete, Zimbabwe-CNRS

12 HERD (Hwange Environmental Research Development) program.

14 Correspondence author: Lucie Thel, lucie.mc.thel@gmail.com. 


\section{Abstract}

In large herbivores, the timing of births is mainly driven by the seasonal availability of their food resource. Population dynamics is strongly influenced by juvenile survival and recruitment, which highly depend on whether individuals are born during a favourable period or not. If births often occur during the most suitable season in northern cyclical environments for many large herbivore species, zebra give birth year-round at Hwange National Park, Zimbabwe, a tropical bushland characterized by the succession of a favourable wet season and a less favourable dry season. We used capture-recapture models for analysing long term observation data collected between 2008 and 2019 in this zebra population. We investigated the effect of the season (as a categorical variable) and the time spent in dry season on three categories of juveniles (younger foals of less than six months old, older foals between six and twelve months old, and yearlings between one and two years old) and mares survival, according to their reproductive state. The season had no effect on any survival. Younger foals annual survival was not affected by the time spent in dry season, whereas older foals and yearlings annual survival decreased with an increasing exposure to the dry season. Mares annual survival also decreased with an increasing time spent in dry season, whatever the reproductive status, but to a large extend when nonreproducing. The timing of birth, by determining the external conditions experienced by the offspring and their mothers during critical phases of their life cycle, plays a determinant role in their survival. As climate change is expected to lead to more frequent droughts, longer and harsher dry seasons in tropical ecosystems, we hypothesize a detrimental effect on zebra population dynamics in the future.

Keywords: capture-mark-recapture, environmental seasonality, Equus quagga, Hwange National Park, reproduction, tropical ecosystem. 


\section{Introduction}

The timing of births, determined by environmental, biotic and internal factors, is a major life history trait of the organisms, involved in the determination of individual fitness and survival (Plard et al. 2015). Although the demographic role of the phenology of reproduction, i.e. the distribution of a reproductive event such as births across the year in a given population, has been illustrated theoretically (e.g. Calabrese and Fagan 2004 in plants and insects), its empirical support is less clear (e.g. Franks et al. 2018 in birds). This is particularly true for large herbivores (Plard et al. 2014), where it has been only marginally explored because of various limitations (e.g. need for detailed long-term individual-based datasets, Clutton-Brock and Sheldon 2010).

The timing of birth and the following months are associated with a critical period for the newborn and its mother in terms of energetic demand: early growth for the former and lactation for the latter (Bronson 1989). In large herbivores, juvenile survival is regulated by various factors such as population size via density-dependent effects (Gaillard et al. 1998) and predation (Severud et al. 2019), but above all, environmental conditions. Juvenile survival depend on the environmental seasonality (sensu Heldstab et al. 2018), i.e. the succession of the seasons defined by an ensemble of environmental and climatic characteristics, with a reduced survival during the harshest season. For instance, calves survival is lower during the dry season than during the wet season in Serengeti wildebeest Connochaetes taurinus (Mduma et al. 1999). Hence, by determining the environmental conditions experienced by the new individual during its first months of life, the timing of birth has indirect consequences on newborn survival, through the modification of its growth rate for instance (e.g. Feder et al. 2008).

Thus, the phenology of birth is generally supposed to be adjusted to maximize offspring survival. In large herbivores, this mainly goes through the synchronization of parturition with food resource availability and quality (Post et al. 2003). Bighorn sheep Ovis canadensis for 
64

instance, give birth during a restricted period of time, just before the forage quality peak, to provide sufficient milk and high-quality vegetation access to their growing lambs (FestaBianchet 1988). Nevertheless, numerous species are characterized by highly variable dates of birth inside their population, even when living in seasonal environments (e.g. Sinclair et al. 2000). Why such a variability, and what are the demographic consequences of this variability? Still few studies have explored the consequences of the timing of birth on early life-stages survival in tropical ungulates, and most of them did not correct for imperfect detection (Gaillard et al. 2000, Grange et al. 2015), leading to less reliable conclusions. Thus, this field of research remains poorly known and needs further explorations (Lee et al. 2017).

In addition, the period around parturition is also critical for reproductive females themselves, as they endure their offspring needs in addition to their own. Lactation costs are particularly high in mammals (Clutton-Brock et al. 1989), and could turn reproductive females more susceptible to environmental conditions. Therefore, lactating females have to adjust their foraging behaviour to meet the extra energetic requirements. In zebra Equus burchellii, lactating mares do not increase their feeding time to keep matching the activity budget of the rest of their harem, but increase their bite frequency when feeding (Neuhaus and Ruckstuhl 2002). They also lead their harem more frequently than non-lactating mares to initiate movements to waterholes due to their increased water demand (Fischhoff et al. 2007). However, if a higher mortality rate could have been observed in females undergoing nursing energetic costs than in those who did not raise an offspring during the same year (Clutton-Brock et al. 1983), this does not appear to be the rule. A large literature, mainly based on northern hemisphere species, found no or positive correlation between the reproductive state and survival in mammal females, depending on their age class, social status or overall quality for instance (e.g. Weladji et al. 2008, Descamps et al. 2009, Morano et al. 2013). The absence of clear pattern and the low representation of species from the southern hemisphere spurs further investigations. 
Here we investigated the effect of the phenology of births on juvenile and mother annual survival in relation to environmental conditions in wild plains zebra Equus quagga. We explored the impact of the time spent in dry season, defined by the timing of birth and the duration of the associated dry season, on the survival of two juvenile stages, yearlings and adult females. We took advantage of a population of individually known animals living in Hwange National Park (HNP), Zimbabwe and followed since 2004. Even if their environment is seasonal (i.e. characterized by the succession of a wet and a dry season, Chamaillé-Jammes et al. 2006), zebras breed year round in this study site. Coupled with a high inter-annual variability in the starting date of the seasons, this constitutes the adequate framework to study the impact of variable environmental conditions related to seasonality on juveniles and females survival during the reproductive period, in a tropical herbivore.

As a large-bodied species living in a seasonal environment, the plains zebra is supposed to belong to the capital end of the capital-income breeder continuum (Jonsson 1997, Ogutu et al. 2014). Once the mother is engaged in reproduction, she will provide the energetic effort to bring her foal to weaning age mainly using previously stored resources. Moreover, newborn almost exclusively rely on its mother for food provisioning through lactation and nursing (Jackson et al. 2021), and is not exposed to thermo-regulation issues in our tropical study site. Thus, we hypothesized foals survival should not be sensitive to environmental conditions until weaning (i.e. during the first six months of life) (i). Then, the foal becoming progressively independent from its mother during the following six months (i.e. between six and 12 months of age, Smuts 1976), it should experience a subsequent decrease in its survival probability (ii). We expected a similar trend in yearling (i.e. between one and two years old) survival (Gaillard et al. 2000) because at this stage, it is fully independent from its mother but not fully grown yet (iii). To the contrary, the period immediately following parturition should be critical for the mother, which could experience lower survival than a non-breeding female (iv-1) and a stronger 
negative response to harsh environmental conditions (v-1). Besides, regarding the variability in the findings associated with the literature focusing on reproductive females survival and the possible confounding effect of mares quality, we also considered the alternative hypothesis that a reproductive female could instead experience higher survival than a non-reproductive one (iv2) and show less sensitivity to harsh environmental conditions (v-2).

\section{Materials and methods}

\section{Context of the study}

\subsection{Study site}

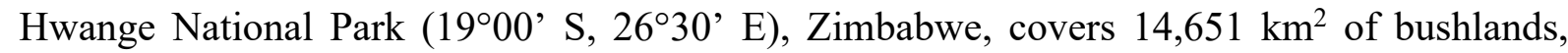
woodlands and scrublands interspersed with grassland (Arraut et al. 2018), at between 900 and $1,100 \mathrm{~m}$ a.s.1.. Average annual rainfall is c. $600 \mathrm{~mm}$, with high inter-annual variations (Chamaillé-Jammes et al. 2006). Most, if not all, rainfall events occur during the wet season from October to April. The start of the wet season is characterised by a high inter-annual variability, leading to variable duration of the dry season. The study took place in the north-east of the park where artificial waterholes retain water year round and where areas $>8 \mathrm{~km}$ from a waterhole are rare, even in the dry season (Chamaillé-Jammes et al. 2007). There is no hunting in the park, but the densities of the two main zebra predators, lion Panthera leo, and spotted hyena Crocuta crocuta are high (Loveridge et al. 2007, Drouet-Hoguet 2007).

\subsection{Study species}

Plains zebras live in harems composed of a stallion, several mares and their foals under two years old (Klingel 1969). They give birth year-round in most of their range, including Zimbabwe (Dasmann and Mossman 1962), even if a births peak can be observed around January to March in this area. Foals are weaned around 11 months of age (Smuts 1976), and 
139 are considered as "followers" on the hider-follower gradient (Lent 1974), as they stand and

140 follow their mother soon after birth (Sinclair et al. 2000). Zebras are grazers, feeding virtually

141 only on grasses. Their food resource is thus mainly driven by rainfall (DuPlessis 2001). In HNP,

142 the population of zebras is mostly resident (unpublished GPS data).

\subsection{Zebra demographic data}

145 Following the protocol presented in Grange et al. (2015), we recorded the presence of individually identified zebras between 2008 and 2019 using visual identification of their unique sessions (hereafter called "sessions") at the transition between wet and dry seasons $(n=24$

149 sessions, mean session duration $=45 \pm 25$ days, range $=13-88$ days). When first sighted, individuals were classified according to three age classes: foal (from birth to 12 months old), yearling (12 to 24 months old) and adults (more than 24 months old). When possible, the precise age of foals and yearlings was determined using the criteria of Smuts 1975 and Penzhorn 1984, and photographs of individuals of known age (see details in Grange et al. 2015). For those

154 individuals, we estimated a date of birth and its accuracy.

\subsection{Season delineation}

157 For each year, we identified the transition date between wet and dry season using $500 \mathrm{~m}$ 158 resolution bi-monthly Normalized Difference Vegetation Index (NDVI) records from the 159 NASA website (MOD13A1 product, https://modis.gsfc.nasa.gov) and daily rainfall records 160 from the Climate Hazards Center website (Rainfall Estimates from Rain Gauge and Satellite

161 Observations, https://www.chc.ucsb.edu)(Supporting information 1). During the study period 162 and according to our estimations, the wet season in HNP started between the $1^{\text {st }}$ of November 
163 and the $19^{\text {th }}$ of December, and the dry season started between the $9^{\text {th }}$ of May and the $29^{\text {th }}$ of 164 July.

\section{Statistical analysis}

\subsection{General purpose}

We ran Capture-Mark-Recapture (CMR) analyses (Lebreton et al. 1992) on two distinct datasets: a first one for individual of known date of birth with an accuracy ranging from 0 to \pm 90 days $(n=310)$ to estimate the annual probability of survival of the two foal age classes (i.e. "younger foals" of less than six months old and "older foals" between six and 12 months old) females $(n=205)$ to estimate the annual probability of survival of mares according to their reproductive state using multi-states models (Lebreton et al. 2009). We tested the effect of the

175 time spent in dry season since births for younger foals and mothers, and the subsequent time spent in dry season between two successive seasons for older foals, yearlings and nonpackage RMark (Laake 2013). The Goodness Of Fit tests (GOF) were assessed using the R package R2ucare (Gimenez et al. 2017). the model specification. We calculated the proportion of time elapsed between two successive sessions pertaining a year as follows: $\Delta t_{s 2-s 1}=\left(\right.$ Start date $_{s 2}-$ Start date $\left._{s 1}\right) / 365$. 
189 As in previous works of demographic analyses performed on these data (Grange et al. 2015,

Vitet et al. 2020, Vitet et al. 2021), we ran the analyses on individuals observed at least once

detected to be pregnant thanks to opportunistic faecal sampling and subsequent hormone (20oxopregnanes and oestrogens, Ncube et al. 2011) dosage ( $n=20$, Supporting information 2).

We recorded those foals as being identified at birth only and never seen again. For both cohort, experimenting similar environmental conditions. We defined three age classes: "younger foals" of less than six months old, "older foals" between six and 12 months old and "yearlings" between one and two years old. Individuals remained in the dataset even after "at least one sighting of the individual during the session $s$ ".

$211=19, P=0.92)$, trap-dependence $\left(\chi^{2}=139.35, d f=17, P<0.01\right)$ and transience $\left(\chi^{2}=70.47, d f\right.$ $212=22, P<0.01)$. After examination of Test $2 . \mathrm{CL}$, we noticed that overdispersion was mainly 
213 caused by three sessions in the dataset. So, we considered it as marginal and ignored overdispersion in the analyses. We took into account trap-dependence by adding a default trap-

Thus, we fitted all survival models tested with a default age class effect. We explored the effect

218 of the season and tids on recapture and survival probabilities, for the two age classes of foals

We also fitted the null models and models including solely a time effect. We conducted a similar analysis on the two foal age classes using a Generalized Linear Model (GLM) approach, presented in Supporting information 4.

\subsection{Mare survival}

225

We ran the analyses on all the adult females observed at least once during the sessions $(n=$

322). The season and tids variables were defined in the same way than for juveniles (see above).

We summarized observations data in a life history dataset, with one observation per known individual per session: 0 corresponding to "no sighting of the mare during the session $s$ ", 1 corresponding to "at least one sighting of the mare alone during the session $s$ " and 2 corresponding to "at least one sighting of the mare with a dependent foal during the session $s$ ".

We considered a dependent foal as an individual that is still suckled, so under 6 months of age.

232 Even if weaning generally occurs around 11 months of age in zebras, foals can survive without 233 their mother from 9 months old upwards (Smut 1976). We chose 6 months to exclude such possibility and match our sessions frequency.

As there were too few repetitions to conduct the GOF tests of the multi-states model, 
dependence $\left(\chi^{2}=112.13, d f=21, P<0.01\right)$ and transience $\left(\chi^{2}=62.23, d f=21, P<0.01\right)$. After examination of Test 2.CL and 3.Sm, we noticed that overdispersion was mainly caused by five and three sessions in the dataset respectively. So overdispersion could be ignored because considered as marginal. We took into account trap-dependence by adding a default trap-

242 dependence effect in each recapture model tested. To take into account transience, we added a

243 categorical covariable sight in all survival models to differentiate between mares captured for 244 the first time during the survey and mares already captured at least once during the survey, 245 following the method described by Pradel et al. 1997. We evaluated the effect of the reproductive state (i.e. with or without a dependent foal), the season and tids on recapture,

247 survival and transition probabilities. Unfortunately, age was not known for a large number of 248 females, so we were not able to include it in the models. We also fitted null models and models including solely a time effect.

\subsection{Model selection}

252 model for the next model selection step. When there was only one competing model emerging

Because of the huge number of combinations possible between recapture and survival (and transition for mares) models, we conducted a two-step selection model using the lowest Akaike Information Criterion adjusted for small sample sizes (AICc) and the number of parameters (principle of parsimony) (Burnham 2002). We conducted a first model selection step on recapture and survival (and transition for mares) models independently. When proceeding to model selection on a given demographic parameter (i.e. recapture, survival or transition), we set the other models to depend exclusively on the covariables related to GOF corrections (e.g. when selecting recapture models in foals, we set survival model as depending on the age class, see Supporting information 3). We considered all the models within $\triangle \mathrm{AICc}<2$ from the best from this model selection step for a given demographic parameter, we also included the second 
263 best model in terms of AICc to allow a real model selection for each of the demographic

264 parameters based on at least two different models (see model selection for data on mares in

265 Supporting information 3).

In the second selection step, we ran all the combinations possible between the best recapture and survival (and transition for mares) models resulting from the first model selection step to identify the best complete models. We retained the complete models (recapture and survival, and transition for mares) within $\triangle \mathrm{AICc}<2$ from the best model as competing models, and we retained the models with the lowest number of parameters as the best models. Following Arnold 2010, we set the confidence intervals at $85 \%$, in accordance with our AICc model 272 selection procedure.

\section{Results}

\section{Juvenile survival}

276 We found four competing models $($ AICc $\in[1718.922 ; 1720.291]$, deviance $\in[1658.641$;

277 1660.011]) to estimate the survival and recapture of juveniles, three of them correspond to the 278 most parsimonious models $(k=29$, see Table 1 and Supporting information 3). In all three 279 models, the probability of recapture included an additive effect of trap-dependence and time, 280 and the probability of survival increased with age and decreased with the proportion of time 281 spent in dry season. The difference between them lied in the effect of tids, which was found to 282 act in addition with the age class, or exclusively on older foals, or on older foals and yearlings 283 grouped together in a unique age category. The season was not retained in the competing 284 models. 
Table 1: Statistics of the four competing models investigating the relationship between annual survival

\begin{tabular}{|l|l|l|l|l|l|}
\hline Model & Explanatory variables & $\begin{array}{l}\text { Nb. of para- } \\
\text { meters }(\mathbf{k})\end{array}$ & AICc & Deviance & DAICc \\
\hline 1 & $\begin{array}{l}\text { Survival } \sim \text { foal_old + yearl + adult + tids * fo_ye } \\
\text { Recapture } \sim \text { td + time }\end{array}$ & 29 & 1718.922 & 1658.641 & 0 \\
\hline 2 & $\begin{array}{l}\text { Survival } \sim \text { foal_old + yearl + adult + tids * fo_ye } \\
\text { Recapture } \sim \text { td + age_class + time }\end{array}$ & 32 & 1719.827 & 1653.049 & 0.906 \\
\hline & $\begin{array}{l}\text { Survival } \sim \text { foal_old + yearl + adult + tids * } \\
\text { foal_old } \\
\text { Recapture } \sim \text { td + time }\end{array}$ & 29 & 1720.134 & 1659.853 & 1.212 \\
\hline 4 & $\begin{array}{l}\text { Survival } \sim \text { age_class + tids } \\
\text { Recapture } \sim \text { td + time }\end{array}$ & 29 & 1720.291 & 1660.011 & 1.37 \\
\hline
\end{tabular}

The following stated results are from Table 1, model 1: the variable tids had a significant negative effect on both older foals and yearlings $(\beta=-0.637 \pm 0.367 \mathrm{SE}, 85 \%$ CI [-1.167; yearlings ranged from $0.891 \pm 0.085 \mathrm{SE}, 85 \% \mathrm{CI}[0.699 ; 0.967]$ to $0.486 \pm 0.123 \mathrm{SE}, 85 \% \mathrm{CI}$ $[0.318 ; 0.657]$. The survival of younger foals was not significantly affected by tids, and was of information 4). Therefore, hypotheses (i) stating that younger foals survival should not be sensitive to environmental conditions, (ii) and (iii) stating that older foals and yearlings resp. 


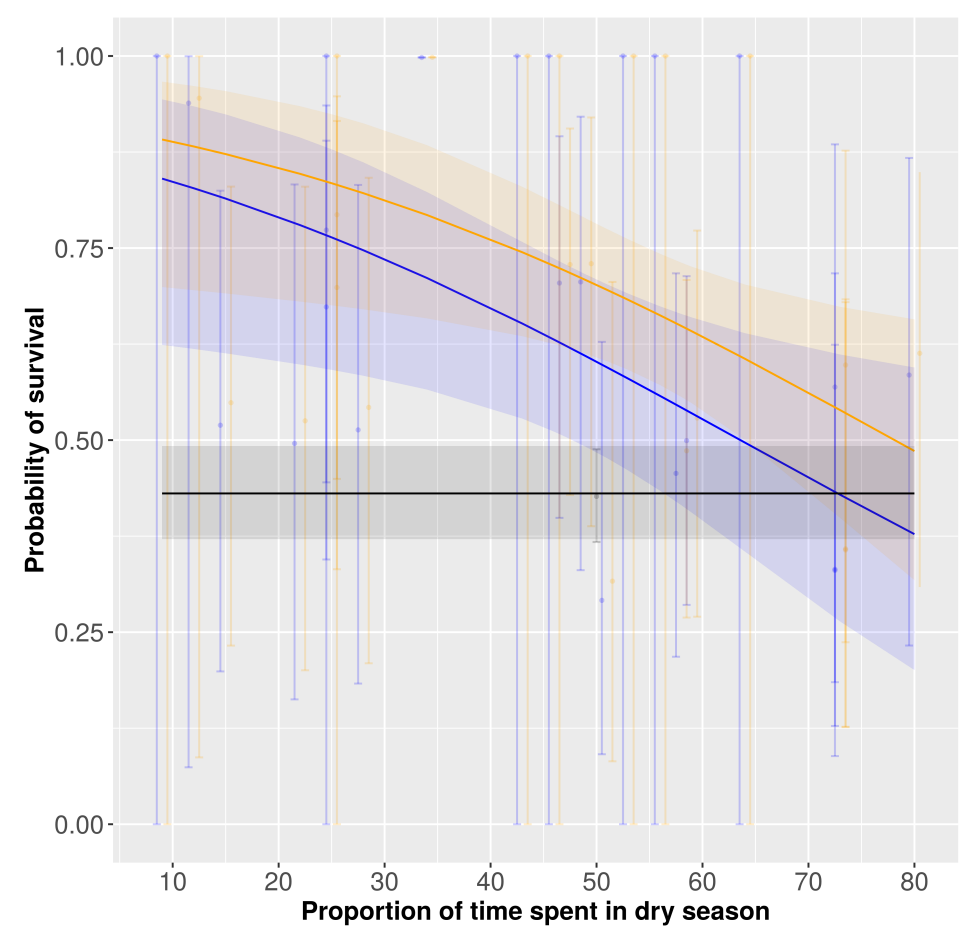

Figure 1: Probability of annual survival of plains zebras juveniles in Hwange Nation Park, Zimbabwe represent $85 \%$ confidence intervals of these predicted values. Dots represent survival predicted by the time model, vertical bars represent $85 \%$ confidence intervals. Scaled proportion of time spent in dry season converted back to the proportion of time spent in dry season.

\section{Mare survival}

We found two competing models $(A I C c \in[3294.197 ; 3295.161]$, deviance $\in[3226.108$; 3224.943]) to estimate the survival, transition between reproductive states and recapture of mares, one of them being the most parsimonious model $(k=33$, see Table 2 and Supporting information 3). In both models, the probability of recapture included an additive effect of the 
322 trap-dependence, reproductive state and time. The probability of survival was higher for

323 reproductive than for non-reproductive mares, and the proportion of time spent in dry season

324 decreased the probability of survival. The probability of transition between reproductive states

325 varied according to the season (see details below). The only difference between the two models

326 came from the fact that tids acted either in addition or in interaction with the reproductive state

327 to predict mares survival.

Table 2 : Statistics of the two competing models investigating the relationship between annual survival and the proportion of time spent in dry season according to the reproductive state in plains zebra mares (Hwange National Park, Zimbabwe, 2008-2019).

\begin{tabular}{|c|c|c|c|c|c|}
\hline Model & Explanatory variables & $\begin{array}{l}\text { Nb. of para- } \\
\text { meters }(k)\end{array}$ & AICc & Deviance & $\triangle \mathrm{AICc}$ \\
\hline 1 & $\begin{array}{l}\text { Survival } \sim \text { sight }+ \text { repro_status }+ \text { tids } \\
\text { Recpature } \sim \text { td }+ \text { repro_status }+ \text { time } \\
\text { Transition } \sim \text { season } * \text { from_repro_status } \\
\text { to repro status }\end{array}$ & 33 & 3294.197 & 3226.108 & 0 \\
\hline 2 & $\begin{array}{l}\text { Survival } \sim \text { sight }+ \text { repro_status } * \text { tids } \\
\text { Recapture } \sim \text { td }+ \text { repro_status }+ \text { time } \\
\text { Transition } \sim \text { season } * \text { from_repro_status } \\
\text { to repro_status }\end{array}$ & 34 & 3295.161 & 3224.943 & 0.964 \\
\hline
\end{tabular}

= reproductive state; from_repro_status = reproductive state of departure for the transition models;

The best-supported model included a significant effect of sight on the survival probability $(\beta=1.075 \pm 0.272 \mathrm{SE}, 85 \% \mathrm{CI}[0.683 ; 1.467])$. Here we present results for mares in their second and following observations only, results relying on a single first observation tids on both reproductive and non-reproductive females $(\beta=-0.729 \pm 0.221 \mathrm{SE}, 85 \% \mathrm{CI}[-$

$3381.047 ;-0.410]$, Fig. 2a). The probability of survival of non-reproductive females varied from 
the shortest to $0.690 \pm 0.060 \mathrm{SE}, 85 \% \mathrm{CI}[0.600 ; 0.769]$ when the proportion of time spent in dry season was the longest. Similarly, the probability of survival of reproductive females varied from $0.989 \pm 0.008 \mathrm{SE}, 85 \% \mathrm{CI}[0.969 ; 0.996]$ to $0.883 \pm 0.054 \mathrm{SE}, 85 \%$ CI $[0.779 ; 0.941]$. Therefore, hypothesis (iv-1) was not validated by our results in favour of hypothesis (iv-2) stating that mothers could experience higher survival than non-breeding females. Similarly, we 345 did not validate hypothesis ( $\mathrm{v}-1)$ in favour of hypothesis (v-2) stating that mothers could experience a lower negative response to harsh environmental conditions. The probability for a

347 mare to move from the reproductive to the non-reproductive state was significantly higher (at 348 least $0.713 \pm 0.044 \mathrm{SE}, 85 \% \mathrm{CI}[0.646 ; 0.772])$ than the probability to stay in the reproductive 349 state (at most $0.287 \pm 0.044 \mathrm{SE}, 85 \%$ CI [0.228; 0.354]) whatever the season (Fig. 2b). The 350 probability to stay in the non-reproductive state was similar to the probability to move from the 351 non-reproductive to the reproductive state in the dry season $(0.486 \pm 0.039 \mathrm{SE}, 85 \% \mathrm{CI}[0.431$; higher in the wet season $(0.688 \pm 0.058 \mathrm{SE}, 85 \% \mathrm{CI}[0.600 ; 0.765]$ against $0.312 \pm 0.058 \mathrm{SE}$, $35485 \%$ CI $[0.235 ; 0.400]$ respectively). The effect of trap-dependence on the probability of 355 recapture was significant $(\beta=1.034 \pm 0.174 \mathrm{SE}, 85 \%$ CI $[0.784 ; 1.284])$. The probability of 356 recapture was higher for non-reproductive than for reproductive females. It varied from 0.411 $357 \pm 0.072 \mathrm{SE}, 85 \%$ CI $[0.313 ; 0.517]$ to $0.908 \pm 0.049 \mathrm{SE}, 85 \%$ CI $[0.808 ; 0.959]$ for non358 reproductive females, and from $0.129 \pm 0.041 \mathrm{SE}, 85 \% \mathrm{CI}[0.080 ; 0.200]$ to $0.676 \pm 0.106 \mathrm{SE}$, $35985 \%$ CI $[0.511 ; 0.807]$ for reproductive females. 

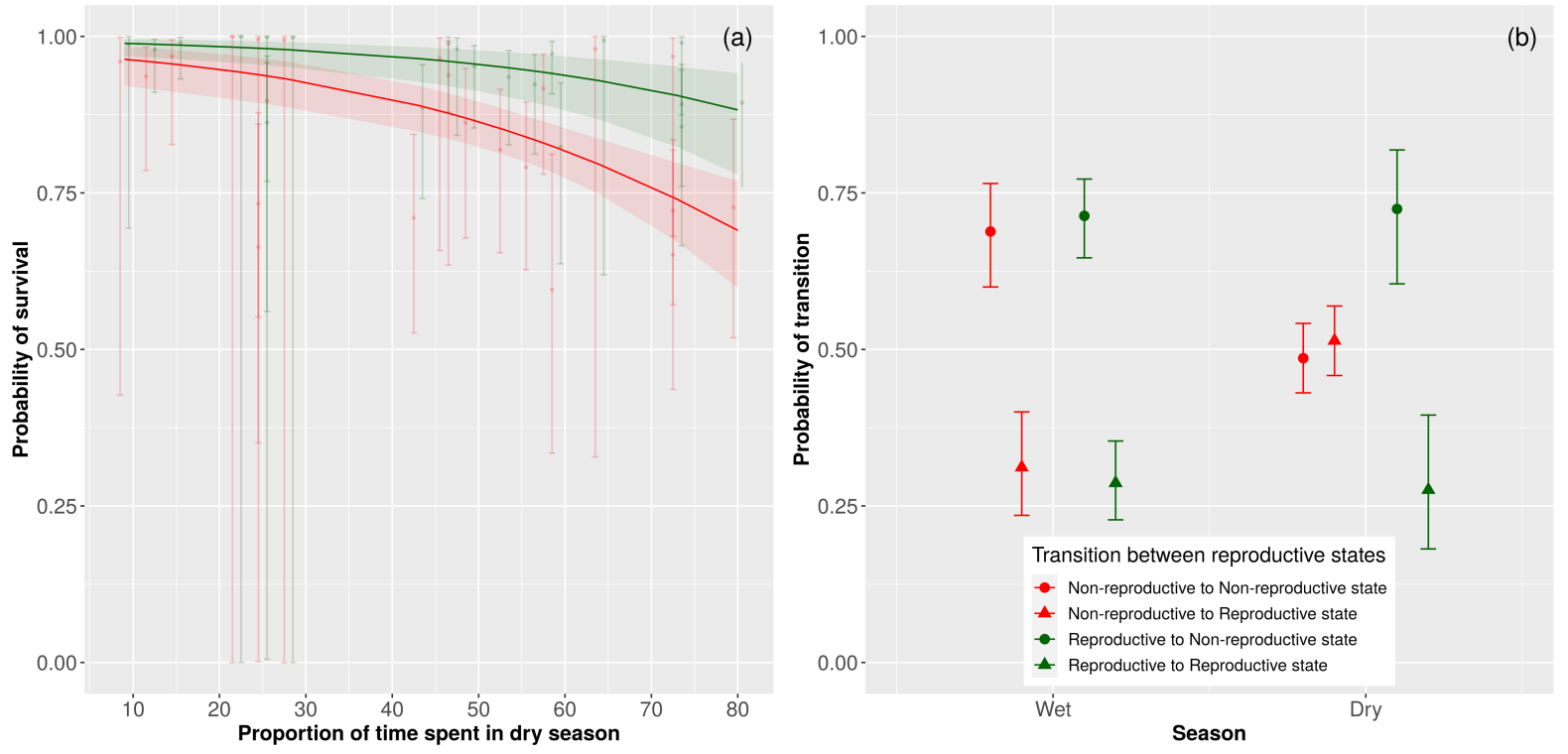

Figure 2: a) Probability of annual survival of plains zebra mares according to the proportion of time

spent in dry season and their reproductive state (for mares in their second and subsequent observations only, see text for details). Solid lines represent predicted values from the best model (red: non-

reproductive females, green: reproductive females). Shaded areas represent $85 \%$ confidence intervals of these predicted values. Dots represent females survival predicted by the time model respectively, vertical bars represent $85 \%$ confidence intervals. Scaled proportion of time spent in dry season converted back

to the proportion of time spent in dry season. b) Probability of transition between reproductive and nonreproductive states for plains zebra mares according to the season. Dots represent predicted values from the best model. Vertical bars represent $85 \%$ confidence intervals of these predicted values. For both graphs: data from Hwange Nation Park, Zimbabwe (2008-2019).

\section{Discussion}

373 The phenology of births, by determining the environmental conditions experienced by newborn

374 at birth and during the following months, has major effects on their survival. Although the annual cohort survival of younger foals (between birth and six months old) is stable around 
decline observed, from approx. 0.8 to 0.4 for both age classes, is of a factor two between the shortest and the longest exposure to dry season experienced by juveniles in this study. Mares annual survival is also altered by an increasing time spent in dry season weather they are in a reproductive state (i.e. with a dependent foal) or not, but in a lower extent. However, this effect is all the more strong for non-reproductive females. flexibility in the duration of gestation (Kiltie 1982). As the reproductive cycle of zebra mares lasts slightly more than one year (Ncube et al. 2011), even if they experience post-partum oestrus (Klingel 1969), one can expect their parturition date should progressively be shifted from the optimal period, unless they delay their reproductive cycle to wait for the next favourable birthing period. But a consequence of this is that their inter-birth interval (mean inter-birth interval of $480 \pm 116$ days in the study site, Barnier et al. 2012) would be significantly increased and their lifetime reproductive success decreased (as observed in giraffe the time spent in dry season on reproductive mares annual survival and no effect on annual survival of younger foals, demonstrating that the timing of birth seems not to be crucial for them. Moreover, females can engage reproduction only when they reach a certain threshold in body condition (Grimsdell 1973), which can be delayed in case of adverse environmental conditions during the year preceding parturition, such as drought years (Ogutu et al. 2014). This is thus a supplementary factor acting as a constraint on the determination of the timing of birth.

398 Altogether, these observations argue in favour of breeding year-round in our zebra population 399 in the interest of the mare fitness, as observed in our population. 
offspring, with the most adequate period being not necessarily the same for the mother than for

404

405

406

407

408

409

410

411

412

413

414

415

416

417

418

419

420

421

422

423

424

425

426

427 the offspring (Dezeure et al. 2021). In our study, one can hypothesize that the optimal timing of birth for the offspring is situated at the beginning of the dry season: the harsh conditions during early life are buffered by the mother at this time, and the offspring starts to become independent while conditions are improving through the following wet season. Moreover, the foal benefits from higher quality reserves stored by the mother during the previous wet season, as suggested in African large herbivores (Ogutu et al. 2014). To the contrary, the optimal timing of parturition for the mare could be more variable, in order to minimize the inter-birth interval as they are only slightly affected by environmental conditions.

Although the timing of birth defines the environmental conditions experienced at birth, it also determines susceptibility to predation, which is a major factor of mortality in zebra foals (Mills and Shenk 1992) and probably in adults too (Grange et al. 2015). On the one hand, the dry season implies higher water demand (which shall be added to the already increased demand of lactating mares) while its availability is reduced. As water holes are hot spots of predation (zebras use movement strategies to minimize risk such as diel migration, Courbin et al. 2018), one can expect a higher predation risk on foals and mares during this season. This could explain their higher mortality as the time spent in dry season increases. On the other hand, they could also benefit from an interaction between environmental conditions and predation during the dry season: the reduced vegetation cover could improve predator detectability and reduce the exposure of zebras to predation (Lee et al. 2017). It is necessary to explore the interactive effect of environmental conditions and predation as defined by the timing of birth to understand their concurrent effect on juvenile survival in tropical ecosystems.

We did not have information about the quality of the mares of our population, whereas it is known to influence reproductive success in other large herbivore species, as illustrated by a lower offspring survival or a lower probability to breed in lower quality females (Hamel et al. 
2009). These observations are nevertheless indirectly supported by our data too, as non-

reproductive females were more sensitive to the time spent in dry season with a survival reproduction or lost their foal at an early stage. of birth (ranging from \pm 0 to 90 days) together with the gathering of foals in discrete periods of births could have limited the robustness of our analyses. However, the same analysis conducted foals and yearlings survival ( $\beta=-0.571 \pm 0.430 \mathrm{SE}, 85 \% \mathrm{CI}[-1.191 ; 0.048]$, results not shown).

443 In addition, the low detectability of early dead foals limits the ability to spot them in the field.

444 However, the opportunistic faecal samples coupled with the hormone dosage conferred a major strength to this study by allowing the detection of a consistent number of probable early dead foals $(n=20)$ and their inclusion in the foals survival estimations, even if the cause and age of death remained unknown.

In large ungulates, juvenile survival and then recruitment have long term consequences 449 on the population dynamics (Gaillard et al. 2000, Raithel et al. 2007). The phenology of births, by determining the external conditions experience at birth and then the timing of the first critical

451 phases of the life cycle of the individuals (e.g. early growth, age at sexual maturity), plays a 452 determinant role in the quality of the cohort produced (Holmes et al. 2021), affecting in turn 
453 the population growth rate. In the southern hemisphere, climate change is expected to lead to

454 an increasing frequency of droughts and of their unpredictability, but also to longer and harsher

455 dry seasons in general (Zhao and Dai 2015, Dunning et al. 2018). The latter, associated with a

456 lower survival of older foals and yearlings as the time spent in dry season increases, could affect

457 the population dynamics of zebras. However, as southern species already live in unpredictable

458 environments to a certain extent (Owen-Smith and Ogutu 2013), one could expect phenotypic

459 adjustments in the timing of birth could occur in response to the changing climate, as it is

460 already observed in drought years in topi or warthog (Ogutu et al. 2010). Phenotypic

461 adjustments are more likely than evolutionary processes, which seems overall less frequently

462 observed in response to climate change (Hoffmann and Sgrò 2011), in particular in species with

463 a long generation time.

464

465 Declarations

466 Funding: This work was supported by a grant from the "Ministère Français de l'Enseignement

467 Supérieur, de la Recherche et de l'Innovation" through the "Ecole Doctorale E2M2" of the

468 "Université Claude Bernard Lyon 1".

469 Authors' contributions: SCJ, CB and LT conceived the ideas and designed methodology; SCJ

470 organised data collection; LT, CB and SCJ analysed the data; LT, SCJ and CB led the writing

471 of the manuscript. All authors contributed critically to the drafts and gave final approval for 472 publication. 


\section{References}

474 Arnold, T. W. 2010. Uninformative parameters and model selection using Akaike's Information Criterion. - J. Wildl. Manage. 74: 1175-1178.

Arraut, E. M. et al. 2018. The 2013--2014 vegetation structure map of Hwange National Park, Zimbabwe, produced using free satellite images and software. - Koedoe African Prot. Area Conserv. Sci. 60: 1-10.

479

Barnier, F. et al. 2012. Inter-birth interval in zebras is longer following the birth of male foals than after female foals. - Acta Oecologica 42: 11-15.

Bronson, F. H. 1989. Mammalian reproductive biology. - University of Chicago Press.

Calabrese, J. M. and Fagan, W. F. 2004. Lost in time, lonely, and single: reproductive asynchrony and the Allee effect. - Am. Nat. 164: 25-37.

484

Chamaillé-Jammes, S. et al. 2006. Spatial patterns of the NDVI--rainfall relationship at the seasonal and interannual time scales in an African savanna. - Int. J. Remote Sens. 27: $5185-5200$.

Chamaillé-Jammes, S. et al. 2007. Climate-driven fluctuations in surface-water availability and the buffering role of artificial pumping in an African savanna: Potential implication for herbivore dynamics. - Austral Ecol. 32: 740-748.

Clutton-Brock, T. and Sheldon, B. C. 2010. Individuals and populations: the role of long-term, individual-based studies of animals in ecology and evolutionary biology. - Trends Ecol. Evol. 25: 562-573.

494

Clutton-Brock, T. H. et al. 1983. The costs of reproduction to red deer hinds. - J. Anim. Ecol.: $367-383$.

Clutton-Brock, T. H. et al. 1989. Fitness costs of gestation and lactation in wild mammals. - 
497 Courbin, N. et al. 2019. Zebra diel migrations reduce encounter risk with lions at night. - J. Anim. Ecol. 88: 92-101.

Dasmann, R. F. and Mossman, A. S. 1962. Reproduction in some ungulates in Southern Rhodesia. - J. Mammal. 43: 533-537.

Descamps, S. et al. 2009. Survival costs of reproduction vary with age in North American red squirrels. - Proc. R. Soc. B Biol. Sci. 276: 1129-1135.

Dezeure, J. et al. 2021. Birth timing generates reproductive trade-offs in a non-seasonal 504 breeding primate. - Proc. R. Soc. B 288: 20210286.

Drouet-Hoguet, N. 2007. Influence des activités anthropogéniques sur le régime alimentaire et la réponse numérique de la hyène tachetée en savane arborée dystrophique dominée par l'éléphant.

Du Plessis, W. P. 2001. Effective rainfall defined using measurements of grass growth in the Etosha National Park, Namibia. - J. Arid Environ. 48: 397-417.

Dunning, C. M. et al. 2018. Later wet seasons with more intense rainfall over Africa under future climate change. - J. Clim. 31: 9719-9738.

512 Feder, C. et al. 2008. Never too late? Consequences of late birthdate for mass and survival of bighorn lambs. - Oecologia 156: 773-781.

Festa-Bianchet, M. 1988. Birthdate and survival in bighorn lambs (Ovis canadensis). - J. Zool. 214: 653-661.

Fischhoff, I. R. et al. 2007. Social relationships and reproductive state influence leadership roles in movements of plains zebra, Equus burchellii. - Anim. Behav. 73: 825-831.

518 Franks, S. E. et al. 2018. The sensitivity of breeding songbirds to changes in seasonal timing is linked to population change but cannot be directly attributed to the effects of trophic asynchrony on productivity. - Glob. Chang. Biol. 24: 957-971. 
521 Gaillard, J.-M. et al. 1998. Population dynamics of large herbivores: variable recruitment with constant adult survival. - Trends Ecol. Evol. 13: 58-63.

523

524

525

526

527

528

529

530

531

532

533

534

535

536

537

538

539

540

541

542

543

544

Gaillard, J.-M. et al. 2000. Temporal variation in fitness components and population dynamics of large herbivores. - Annu. Rev. Ecol. Syst. 31: 367-393.

Gimenez, O. et al. 2017. R2ucare: Goodness-of-Fit Tests for Capture-Recapture Models. in press.

Gimenez, O. et al. 2018. R2ucare: An R package to perform goodness-of-fit tests for capturerecapture models. - bioRxiv: 192468.

Grange, S. et al. 2015. Demography of plains zebras (Equus quagga) under heavy predation. Popul. Ecol. 57: 201-214.

Grimsdell, J. J. 1973. Reproduction in the African buffalo, Syncerus caffer, in western Uganda. - J. Reprod. Fertil. Suppl. 19: 303.

Hamel, S. et al. 2009. Individual variation in reproductive costs of reproduction: High-quality females always do better. - J. Anim. Ecol. 78: 143-151.

Heldstab, S. A. et al. 2018. Geographical Origin, Delayed Implantation, and Induced Ovulation Explain Reproductive Seasonality in the Carnivora. - J. Biol. Rhythms 33: 402-419.

Hoffmann, A. A. and Sgrò, C. M. 2011. Climate change and evolutionary adaptation. - Nature 470: 479-485.

Holmes, S. M. et al. 2021. Declining recruitment and mass of Swedish moose calves linked to hot, dry springs and snowy winters. - Glob. Ecol. Conserv. 27: e01594.

Jackson, N. J. et al. 2021. Demographic performance of a large herbivore: effects of winter nutrition and weather. - Ecosphere 12: e03328.

Jönsson, K. I. 1997. Capital and income breeding as alternative tactics of resource use in reproduction. - Oikos 78: 57-66. 
545 K.P. Burnham, D. R. A. 2002. Model Selection and Multimodel Inference - A Practical Information-Theoretic Approach. - Springer Verlag, New York, USA.

547 Kiltie, R. A. 1982. Intraspecific variation in the mammalian gestation period. - J. Mammal. 63: $646-652$.

549 Klingel, H. 1969. The social organisation and population ecology of the plains zebra (Equus quagga). - African Zool. 4: 249-263.

Laake, J. L. 2013. \{RMark\}: An R Interface for Analysis of Capture-Recapture Data with $\{$ MARK $\}$.

Lebreton, J.-D. et al. 1992. Modeling survival and testing biological hypotheses using marked animals: a unified approach with case studies. - Ecol. Monogr. 62: 67-118.

Lebreton, J.-D. et al. 2009. Modeling individual animal histories with multistate capture-recapture models. - Adv. Ecol. Res. 41: 87-173.

Lee, D. E. et al. 2017. Season of birth affects juvenile survival of giraffe. - Popul. Ecol. 59: 45-

Lent, P. C. 1974. The Behaviour of Ungulates and its relation to management. - In: F., G. V. \& W. (ed), IUCN Publi. International Union for Conservation of Nature and Natural Resources, pp. 14-55.

Loveridge, A. J. et al. 2007. The impact of sport-hunting on the population dynamics of an African lion population in a protected area. - Biol. Conserv. 134: 548-558.

Mduma, S. A. R. et al. 1999. Food regulates the Serengeti wildebeest: a 40-year record. - J. Anim. Ecol. 68: 1101-1122.

Mills, M. G. L. and Shenk, T. M. 1992. Predator--prey relationships: The impact of lion predation on wildebeest and zebra populations. - J. Anim. Ecol.: 693-702. 
Ncube, H. et al. 2011. Pattern of faecal 20-oxopregnane and oestrogen concentrations during pregnancy in wild plains zebra mares. - Gen. Comp. Endocrinol. 172: 358-362.

572

Neuhaus, P. and Ruckstuhl, K. E. 2002. The link between sexual dimorphism, activity budgets, and group cohesion: the case of the plains zebra (Equus burchelli). - Can. J. Zool. 80: 1437-1441.

Ogutu, J. O. et al. 2010. Rainfall extremes explain interannual shifts in timing and synchrony of calving in topi and warthog. - Popul. Ecol. 52: 89-102.

Ogutu, J. O. et al. 2014. Responses of phenology, synchrony and fecundity of breeding by African ungulates to interannual variation in rainfall. - Wildl. Res. 40: 698-717.

Owen-Smith, N. and Ogutu, J. O. 2013. Controls over reproductive phenology among ungulates: allometry and tropical-temperate contrasts. - Ecography (Cop.). 36: 256-263.

Penzhorn, B. L. 1984. A long-term study of social organisation and behaviour of Cape mountain zebras Equus zebra zebra. - Z. Tierpsychol. 64: 97-146.

Plard, F. et al. 2014. Mismatch between birth date and vegetation phenology slows the demography of roe deer. - PLoS Biol. 12: e1001828.

Plard, F. et al. 2015. The influence of birth date via body mass on individual fitness in a longlived mammal. - Ecology 96: 1516-1528.

Post, E. et al. 2003. Synchrony between caribou calving and plant phenology in depredated and non-depredated populations. - Can. J. Zool. 81: 1709-1714.

Pradel, R. et al. 1997. Capture-recapture survival models taking account of transients. Biometrics: 60-72.

Raithel, J. D. et al. 2007. Impact of spatial and temporal variation in calf survival on the growth of elk populations. - J. Wildl. Manage. 71: 795-803.

Severud, W. J. et al. 2019. Survival and cause-specific mortality of moose calves in northeastern Minnesota. - J. Wildl. Manage. 83: 1131-1142. 
595 Sinclair, A. R. E. et al. 2000. What determines phenology and synchrony of ungulate breeding in Serengeti? - Ecology 81: 2100-2111.

597 Smuts, G. L. 1975. Pre-and postnatal growth phenomena of Burchell's zebra Equus burchelli 598 antiquorum. - Koedoe 18: 69-102.

599 Smuts, G. L. 1976. Reproduction in the zebra mare Equus burchelli antiquorum from the $600 \quad$ Kruger National Park. - Koedoe 19: 89-132.

601 Vitet, C. et al. 2020. Plains zebras bring evidence that dilution and detection effects may not 602 always matter behaviorally and demographically. - Ecosphere 11: e03288.

603 Vitet, C. et al. 2021. Do infanticides occur in harem-forming equids? A test with long-term sociodemographic data in wild plains zebras. - Anim. Behav. 177: 9-18.

605 Weladji, R. B. et al. 2008. Heterogeneity in individual quality overrides costs of reproduction 606 in female reindeer. - Oecologia 156: 237-247.

607 Zhao, T. and Dai, A. 2015. The magnitude and causes of global drought changes in the twentyfirst century under a low--moderate emissions scenario. - J. Clim. 28: 4490-4512. 